УДК 622.271.3.06:658.527

\title{
ОЦЕНКА ЭФФЕКТИВНОСТИ ЦИКЛИЧНО-ПОТОЧНОЙ ТЕХНОЛОГИИ В УСЛОВИЯХ СОВРЕМЕННЫХ КАРЬЕРОВ
}

\author{
Журавлев Артем Геннадиевич1, \\ juravlev@igduran.ru
}

\author{
Семенкин Александр Владимирович1, \\ semenkin@lgduran.ru \\ 1 Институт горного дела Уральского отделения Российской академии наук,
Россия, 620219, г. Екатеринбург, ул. Мамина-Сибиряка, 58.
}

Актуальность исследования заключается в том, что применение циклично-поточной технологии в рациональных для нее условиях позволяет заметно сократить затраты на транспортирование горной массы, однако имеет особенности и ограничения, в частности большой объем капитальных затрат. Поэтому необходимо применение методик, обеспечивающих достоверный расчет окупаемости проекта и оптимизацию его технико-экономических параметров.

Цель: на основе анализа чистого дисконтированного дохода установить области экономичного применения комплексов циклично-поточной технологии в сравнении с экскаваторно-автомобильными комплексами.

Объекты: горнотехнические факторы комплексов циклично-поточной технологии и экскаваторно-автомобильных комплексов (годовая производительность, высота подъема горной массы, вид транспортируемой горной массы, технологические особенности размещения дробильно-конвейерного комплекса в карьерном пространстве)

Методы: научный и технико-экономический анализ, графооналитический.

Результаты. Приводится обзор применения современных комплексов ииклично-поточной технологии на карьерах России. Показаны результаты расчета экономического эфффекта от применения комплексов ииклично-поточной технологии в сравнении с экскаваторно-автомобильными комплексами по методике, разработанной в ИГД УрО РАН. В результате исследования определен срок окупаемости дополнительных инвестиций на вскрышной комплекс циклично-поточной технологии с разносом борта карьера, учитывающий дисконтирование затрат, при различных технологических параметрах (высота подъема горной массы от 180 до 680 м, годовая производительность комплексов от 5 до 30 млн m/2од). Показано изменение разницы чистого дисконтированного дохода по вариантам циклично-поточная технология-экскаваторно-автомобильный комплекс в зависимости от горнотехнических параметров комплексов. Установлена область наиболее экономичного применения циклично-поточной технологии с ленточными конвейерами стандартного уклона (до $\left.16^{\circ}\right)$ при разносе борта карьера под дробильно-конвейерный комплекс по затратам на транспорт.

\section{Ключевые слова:}

Циклично-поточная технология, дробильно-конвейерный комплекс, технико-экономическое сравнение, область применения, ленточный конвейер.

\section{Введение}

В ближайшей перспективе более распространенным направлением развития мировой горной промышленности считается открытый способ разработки месторождений. В России открытым способом добывается $91 \%$ железных руд, более $70 \%$ руд цветных металлов, более 60 \% угля [1]. Стоимость транспортирования горной массы занимает большую часть общей стоимости добычи $[2,3]$. Применение циклично-поточной технологии в рациональных для него условиях позволяет заметно сократить затраты на транспортирование горной массы в сравнении с наиболее широко используемым автомобильным транспортом [4-6], однако имеет особенности и ограничения, в частности большой объем капитальных затрат. Поэтому, несмотря на значительные преимущества, пока ограниченно применяется на горнодобывающих предприятиях. Тем не менее в последние годы вновь возросло количество реализуемых проектов на отечественных карьерах. Ниже приведены некоторые примеры.

Однако дальнейшее развитие эффективной разработки месторождений открытым способом зависит не только от применения различных видов горнотранс- портного оборудования, но и от внедрения на карьерах современных автоматизированных систем управления горнотранспортными комплексами [1].

В 2015 г. Оленегорский ГОК запустил дробильноконвейерный комплекс (ДКК) с крутонаклонным конвейером (КНК). Инвестиции компании «Северсталь» в реализацию проекта составили более 750 млн р. По оценкам за восемь лет работа комплекса с КНК должна снизить операционные и инвестиционные затраты почти на 1,8 млрд р. за счет уменьшения транспортных расходов, сокращения парка автосамосвалов. КНК возведен в Оленегорском карьере с отметки -65 м до отметки +60 м (корпус крупного дробления), имеет высоту 125 м, длину 252 м и генеральный угол наклонной части $36^{\circ}$. Руда поставляется КНК в ранее существовавший комплекс ЦПТ. Годовая производительность комплекса по руде после крупного и среднего внутрикарьерного дробления составляет до 5,7 млн т железной руды [7].

На Михайловском ГОКе строятся ДКК на юговосточном борту карьера. Дробильно-перегрузочное устройство (ДПУ), расположенное на глубине более 200 м, будет осуществлять приемку руды с автосамосвалов, дробление её до фракции размером 150 мм и 
доставку по подземной галерее до КНК. Угол наклона КНК с прижимной лентой составляет 37 градусов, высота подъема - 215 м. Ввод в эксплуатацию ДКК в южной части карьера Михайловского ГОКа запланирован на 2020 г. Производительность по руде - около 15 млн т/год. Второй этап по строительству крутонаклонного конвейерного подъемника в центральной части карьера производительностью 35 млн т/год планируется завершить в 2023 г. [8]. Инвестиции в проект составят около 11,5 млрд р. [9]. Комплекс мероприятий позволит сократить затраты на транспортировку горной массы за счёт оптимизации технологической схемы карьерного транспорта, сокращения количества перегрузочных пунктов и погрузочного оборудования, уменьшения расстояния перевозок руды железнодорожным транспортом.

Внедрение циклично-поточной технологии (ЦПТ) планируется и на другом объекте «Металлоинвеста» Лебединском ГОКе, инвестиции составят порядка 12,6 млрд р. По проектным оценкам ввод ЦПТ позволит сократить производственную себестоимость концентрата на 17 \% к 2025 г. относительно 2018 г. и обеспечить транспортировку горной массы на фабрику в объеме 55 млн т/год [8].

Одним из современных примеров применения ЦПТ с традиционным ленточным конвейером на карьерах России служит Михеевский ГОК [10]. Михеевское месторождение медно-порфировых руд входит в число 50 крупнейших месторождений мира, его запасы оцениваются в 629 млн т руды. Мощность переработки руды на Михеевском ГОКе - до 27 млн т в год [11]. Горная масса из забоев транспортируется автосамосвалами на Дробильно-перегрузочный пункт
(ДПП), расположенный на борту карьера. Дробление осуществляется в гирационной дробилке, следом руда через бункер подается питателями на передаточный и далее на магистральный ленточный конвейер, доставляющий дробленую руду на склад. Длина ленточного конвейера, расположенного в крытой галерее, составляет $1500 \mathrm{M}$.

Анализ информации об инвестиционных затратах крупных горнодобывающих компаний в строительство комплексов ЦПТ, приводимых в открытых публикациях, показал, что зависимость инвестиций от производственной мощности ДКК близка к прямо пропорциональной с тенденцией к более интенсивному возрастанию в области высоких производительностей (50-60 млн т/год). Вероятно, это связано с уникальностью (в определенной мере) таких технических решений и, соответственно, большей их удельной стоимостью.

Установлено, что характер зависимости капитальных затрат, рассчитанных в ходе теоретических исследований ИГД УрО РАН [12], схож с вышеприведенными фактическими данными рис. 1. Однако для детального анализа требуется рассматривать зависимость технико-экономических показателей не только от производительности, но и от других ключевых факторов: высоты подъема, протяженности конвейера, типа конвейеров (угол наклона, ширина и скорость движения ленты), пропускной способности и степени дробления ДПУ и др. В связи с этим расчетные технико-экономические модели циклично-поточной технологии являются важным инструментом в условиях расширяющегося их внедрения на отечественных горнодобывающих предприятиях.

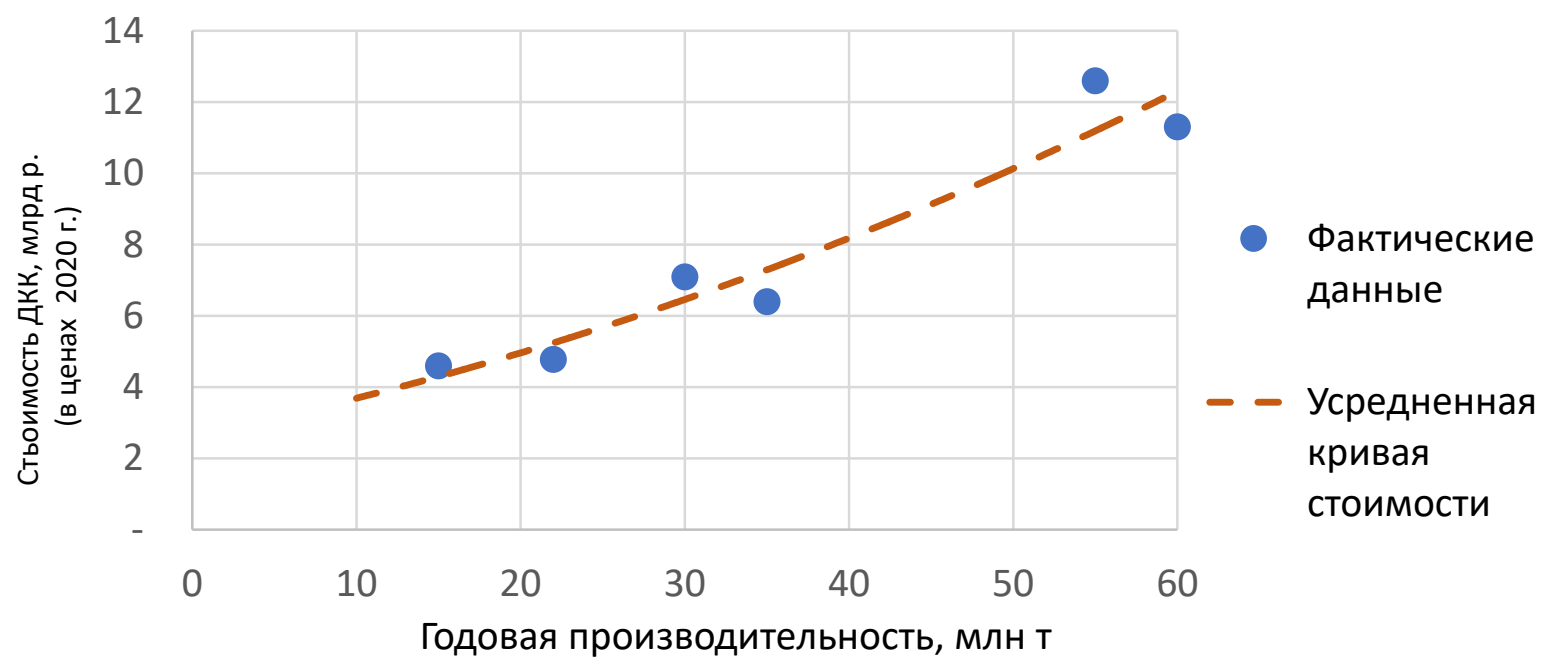

Рис. 1. Оиенка зависимости инвестищий в дробильно-конвейерный комплекс от его производственной мощности (по данным открытых публикаций)

Fig. 1. Assessment of the dependence of investment in a crushing and conveyor complex on its production capacity (according to open publications)

Перспективным направлением в обосновании транспортных систем карьеров является их оптимизация под конкретные условия эксплуатации на основе компьютерного моделирования [13]. Опыт ИГД УрО РАН показывает, что детальный анализ горно- геологических и горнотехнических условий карьера, особенностей организации ведения горных работ и правильный выбор позволяют не только оптимизировать затраты и повысить эффективность ЦПТ благоприятных условиях эксплуатации, но и обосновать 
такие параметры комплексов, которые позволяют расширить границы их эффективного применения в сложных горнотехнических условиях. Это возможно благодаря применению научно обоснованных методик.

Выполненный комплекс исследований позволил создать достаточно простую и удобную на практике экспресс-методику оценки эффективности ЦПТ. Она позволяет оценить затраты в сравнении с автомобильным транспортом в широком диапазоне условий как в относительных единицах, так и с выходом на общепринятые показатели, в том числе чистый дисконтированный доход (ЧДД). Поскольку базовая часть уже изложена в ряде статей $[12,14,15]$, ниже приведены итоговые показатели экономической эффективности ЦПТ, отражающие диапазон горнотехнических условий ее применения в современных условиях.

\section{Методика исследований}

Стоимостные показатели приняты на 2020 г. по предприятиям-аналогам. Области экономичного применения комплексов ЦПТ в сравнении с экскаваторноавтомобильными комплексами определялись путем сравнения ЧДД по вариантам. Расчет ЧДД для всех рассматриваемых вариантов проведен с идентичными горнотехническими условиями, что позволяет достоверно сравнивать варианты. ЦПТ сравнивается с технологическим карьерным автотранспортом (экскаваторно-автомобильным комплексом, далее - ЭАК).

Разница между вскрышными и рудными комплексами заключается в том, что применение ЦПТ подразумевает внутрикарьерное дробление горной массы вне зависимости от ее вида (рудные или вскрышные породы). При использовании ЭАК вскрышные породы транспортируются из карьера в отвал без дробления, а руда поступает на стадию крупного дробления дробильно-обогатительной фабрики (ДОФ), соответственно, затраты на участок крупного дробления включены в вариант ЭАК. Поэтому затраты на дробильное оборудование ЭАК учитываются только на рудном комплексе.

В вариантах ЦПТ высота подъема горной массы от забоя до перегрузочного пункта автосамосвалами принята 80 м. Исследуются комплексы ЦПТ с двумя вариантами схемы расположением в карьере:

- традиционная с разносом борта под конвейерную траншею;

- специальная, предполагающая минимум горнокапитальных работ, выполняемая без разноса борта карьера [14].

Для расчета технологических параметров ЦПТ и ЭАК использована методика, изложенная в работах $[12,14,15]$.

Параметры комплексов ЦПТ и ЭАК представлены в табл. 1, 2, а технологические схемы транспорта - на рис. 2. В качестве ДПУ рассматриваются стационарные установки, монтируемые на железобетонных конструкциях, на базе дробилок производства «Уралмашзавод» [16]. Могут применяться и полустационарные переносимые ДПУ на модульных металлоконструкциях, например, описанные в [17].
Расчет ЧДД выполняется по известной формуле [18]

$$
\text { ЧДД }(N V P)=\sum_{t=0}^{n} \frac{C F_{t}}{(1+r)^{t}},
$$

где $C F_{t}$ (Cash Flow) - потоки денежных средств в конкретный период проекта, которые представляют собой разность притоков и оттоков денежных средств в каждом конкретном периоде $t ; r$ - ставка дисконта, \%; $t-$ период времени, лет.

$$
C F=Д-Э_{3}-\mathrm{K}_{3},
$$

где Д - доходная часть, р.; Э - эксплуатационные затраты, р.; К

$$
\text { ЧДД }=\sum_{t=0}^{n} \frac{Д-Э_{3}-\kappa_{3}}{(1+r)^{t}} \text {. }
$$

При сравнении только транспортных систем, зачастую доходная часть неизвестна. Однако, если привести оба рассматриваемых варианта к сопоставимым видам (условиям), доходные части будут идентичны (одинаковый объем перевозок и стоимость товарной продукции). При этом формула для оценки эффективности применения ЦПТ по разнице между ЧДД на комплекс ЦПТ и ЧДД на ЭАК примет вид:

$$
\begin{aligned}
& \text { ЧДД }{ }_{\Delta}=\text { ЧДД }_{\text {цпт }}-\text { ЧДД } \\
& +\sum_{t=0}^{n} \frac{-Э_{3(\text { цाт })}-\mathrm{K}_{3(\text { цाт })}}{(1+r)^{t}}-\sum_{t=0}^{n} \frac{-Э_{3(\text { эак })}-\mathrm{K}_{3(\text { эак })}}{(1+r)^{t}}= \\
& =\sum_{t=0}^{n} \frac{-Э_{3(\text { цाт) }}-\mathrm{K}_{3(\text { цпт) }}}{(1+r)^{t}}-\sum_{t=0}^{n} \frac{-Э_{3(\text { эак })}-\mathrm{K}_{3 \text { (эак })}}{(1+r)^{t}} \text {. }
\end{aligned}
$$

\section{Результаты исследования}

Ниже приведены графики, отражающие результаты расчета разницы чистых дисконтированных доходов между вариантами ЦПТ и ЭАК. ЦПТ характеризуется более высокими капитальными затратами на оборудование и возведение дробильно-конвейерного комплекса, которые не компенсируются снижением затрат на меньший парк автосамосвалов. В то же время эксплуатационные затраты в варианте ЦПТ меньше, чем при автомобильном транспорте, поэтому график разницы ЧДД с накопительным итогом соответствует классическому графику ЧДД, когда сформированный в первый период отрицательный результат от капиталовложений с течением времени компенсируется экономией затрат.

Для примера на рис. 3 приведены результаты расчетов для вскрышного комплекса ЦПТ производительностью 20 млн т/год при размещении в карьере с разносом борта в сравнении с вскрышным ЭАК. Видно, что с ростом высоты подъема стоимость ДКК возрастает, а потому точка минимума ЧДД (цпт-эАК) смещается вниз, достигая при 680 м (из них 80 м - высота подъема автотранспортом) пятикратной величины относительно варианта с высотой 280 м. В то же время чем больше высота подъема, тем больше сокращение эксплуатационных затрат, поэтому кривые ЧДД(цПт-эАК) нарастают интенсивнее, обеспечивая в длительной перспективе больший экономический эффект. 


\section{І. Рудный комплекс ЭАК (ККД-1500/180 нли ШДІ-15х21У)}

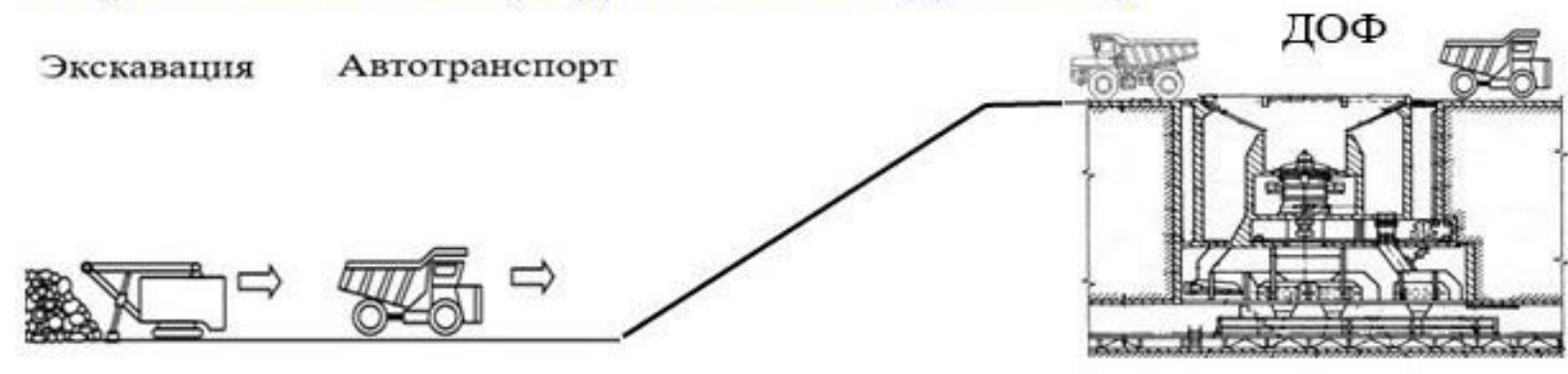

II. Вскрышной комплекс ЭАК

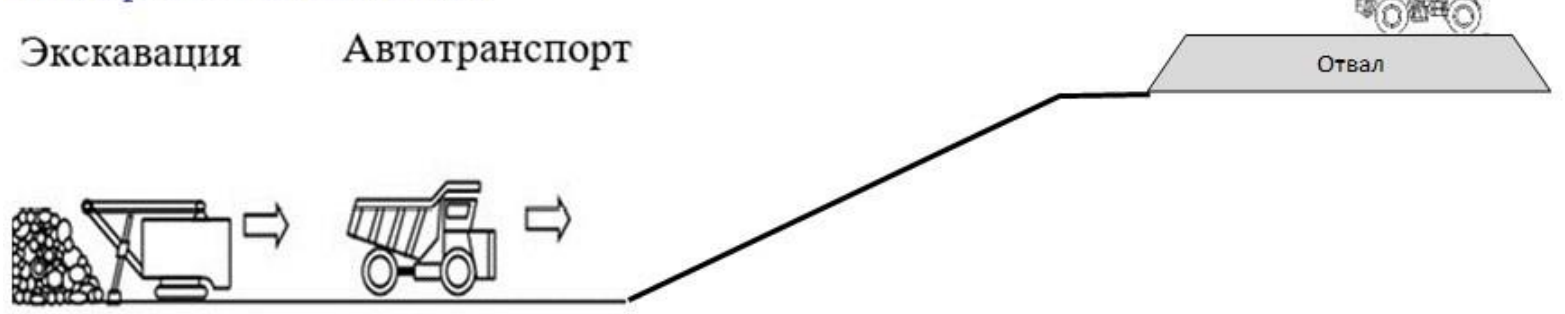

III. Рудный комплекс ЦІТ (ККД-1500/180)

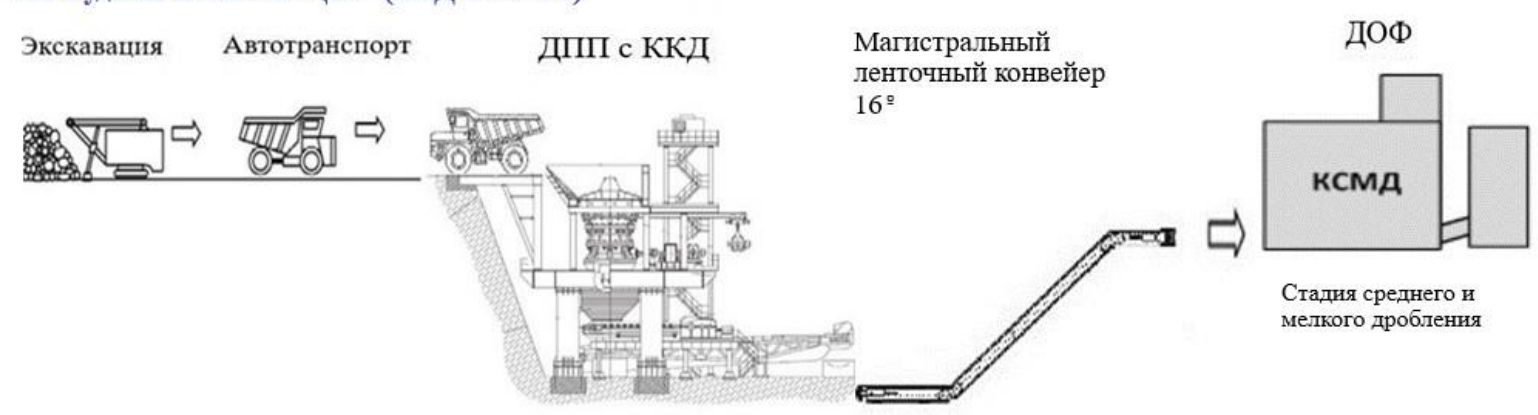

IV. Рудный комплекс Цाт (ЩयП-15х21У)

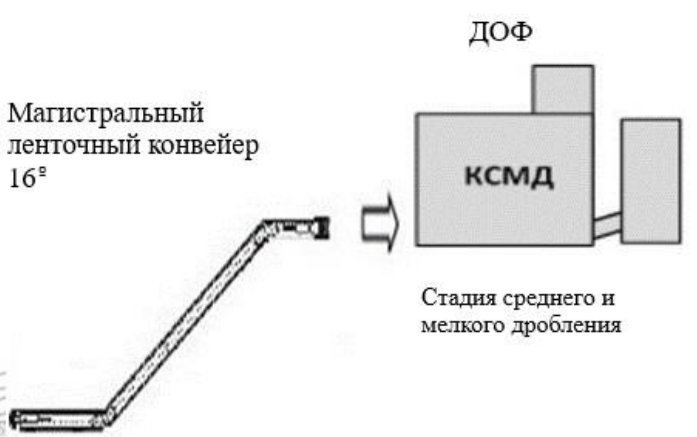

V. Вскрышной комплекс ЦІТ (на примере ККД-1500/180)

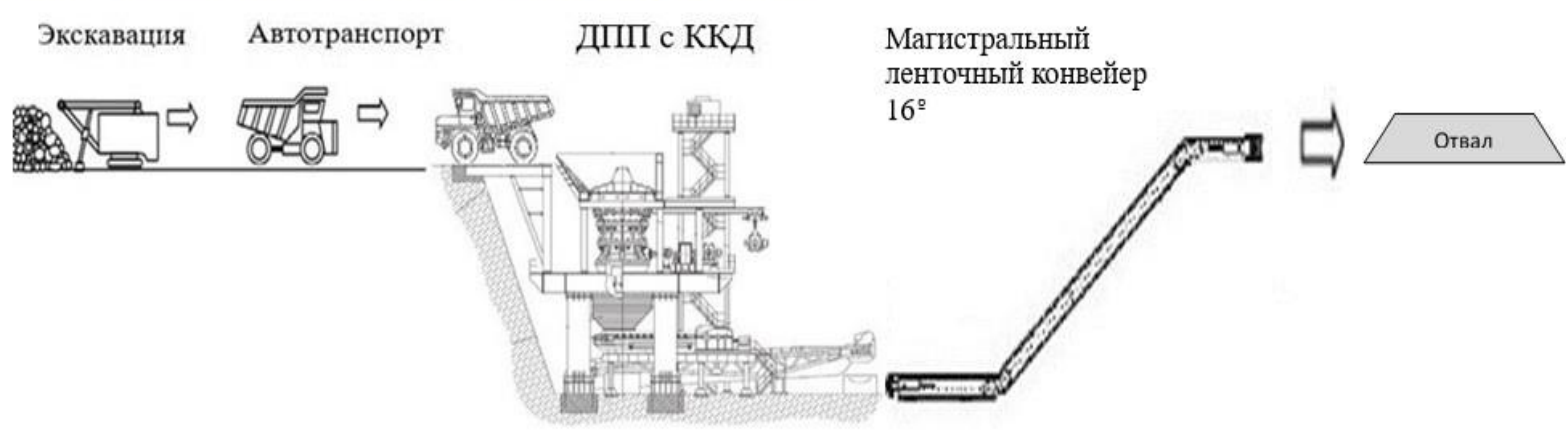

Рис. 2. Технологические схемы транспорта по вариантам

Fig. 2. Technological schemes of transport by options 
Таблица 1. Оборудование в ЭАК

Table 1. Equipment in the excavator and automobile complex (EAC)

\begin{tabular}{|c|c|c|c|c|}
\hline $\begin{array}{l}\text { Годовая производительность, млн т/год } \\
\text { Annual productivity, mln t/year }\end{array}$ & 5 & 10 & 20 & 30 \\
\hline Высота подъема горной массы, м/Lifting height of the rock mass, $m$ & \multicolumn{4}{|c|}{$180-680$} \\
\hline $\begin{array}{l}\text { Расстояние транспортирования горной массы автосамосвалами, км } \\
\text { Distance of rock mass transportation by trucks, } \mathrm{km}\end{array}$ & \multicolumn{4}{|c|}{$\begin{array}{c}\text { Рудный комплекс/Ore complex }-4,6 \\
\text { Породный комплекс/Rock complex - } 11,8\end{array}$} \\
\hline Вместимость ковша экскаватора, $\mathrm{m}^{3} /$ Excavator bucket capacity, $\mathrm{m}^{3}$ & 5 & 12 & 15 & 15 \\
\hline Число экскаваторов, шт./Number of excavators, pcs. & 3 & 5 & 5 & 6 \\
\hline Грузоподъемность автосамосвала, т/Truck load capacity, t & 45 & 90 & 130 & 130 \\
\hline Число автосамосвалов, шт./Number of trucks, pes. & $24-54$ & $24-54$ & $33-74$ & $39-89$ \\
\hline \multicolumn{5}{|c|}{$\begin{array}{c}\text { Рудный комплекс (дополнительно учитывается стоимость дробилки) } \\
\text { Ore complex (additional cost of the crusher is taken into account) }\end{array}$} \\
\hline Тип дробилки рудного комплекса/Type of ore complex crusher & \multicolumn{2}{|c|}{ ЩДП 15×21У } & \multicolumn{2}{|c|}{ ККД-1500/180 } \\
\hline Числодробилок, шт./Number of crushers, pcs & 1 & 2 & 1 & 2 \\
\hline Схема (по рис. 2)/Scheme (according to fig. 2) & \multicolumn{4}{|c|}{1} \\
\hline
\end{tabular}

Таблица 2. Параметры оборудования в комплексах ЦПТ

Table 2. $\quad$ Parameters of the equipment in the complexes cyclic-flow technology $(C F T)$

\begin{tabular}{|c|c|c|c|c|}
\hline $\begin{array}{c}\text { Годовая производительность, млн т/год } \\
\text { Annual productivity, mln t/year }\end{array}$ & 5 & 10 & 20 & 30 \\
\hline $\begin{array}{l}\text { Высота подъема горной массы, м } \\
\text { Lifting height of the rock mass, m }\end{array}$ & \multicolumn{4}{|c|}{$\begin{array}{l}\text { 180-680 (в т. ч. автотранспорт - } 80 \text { м) } \\
\text { (including trucks }-80 \mathrm{~m} \text { ) }\end{array}$} \\
\hline $\begin{array}{l}\text { Расстояние транспортирования горной массы конвейером, м } \\
\text { Distance of transportation of rock mass on the conveyor, m }\end{array}$ & \multicolumn{4}{|c|}{ 324-1944 } \\
\hline Тип дробилки/Type of crusher & \multicolumn{2}{|c|}{ ЩДП $15 \times 21 \mathrm{У}$} & \multicolumn{2}{|c|}{ ККД-1500/180 } \\
\hline Числодробилок, шт./Number of crushers, pcs & 1 & 2 & 1 & 2 \\
\hline Число питателей, шт./Number of feeders, pcs & 1 & 2 & 2 & 4 \\
\hline Схема (по рис. 2)/Scheme (according to fig. 2) & \multicolumn{2}{|c|}{ IV } & \multicolumn{2}{|c|}{ III, V } \\
\hline $\begin{array}{l}\text { Оконечное оборудование ДКК } \\
\text { Termination equipment of the crushing-conveyor complex }\end{array}$ & \multicolumn{4}{|c|}{$\begin{array}{l}\text { Рудный комплекс - нет/Ore complex is not } \\
\text { Породный комплекс - отвалообразователь } \\
\text { Rock complex - dumper }\end{array}$} \\
\hline Ширина ленты, м/Width of the belt, $\mathrm{m}$ & 1 & 1 & 1,4 & 1,6 \\
\hline Длина става, м/Length of column, $m$ & $324-972$ & $324-486$ & $324-390$ & 324 \\
\hline Число ставов, шт./Number of structures, pcs & $1-2$ & $1-4$ & $1-5$ & $1-6$ \\
\hline Вместимость ковша экскаватора, $\mathrm{m}^{3} /$ Excavator bucket capacity, $\mathrm{m}^{3}$ & 5 & 12 & 15 & 15 \\
\hline Число экскаваторов, шт./Number of excavators, pcs & 3 & 5 & 5 & 6 \\
\hline Грузоподъемность автосамосвала, т/Truck load capacity, t & 45 & 90 & 130 & 130 \\
\hline Число автосамосвалов, шт./Number of trucks, pcs & 12 & $12-13$ & $16-18$ & $20-24$ \\
\hline
\end{tabular}

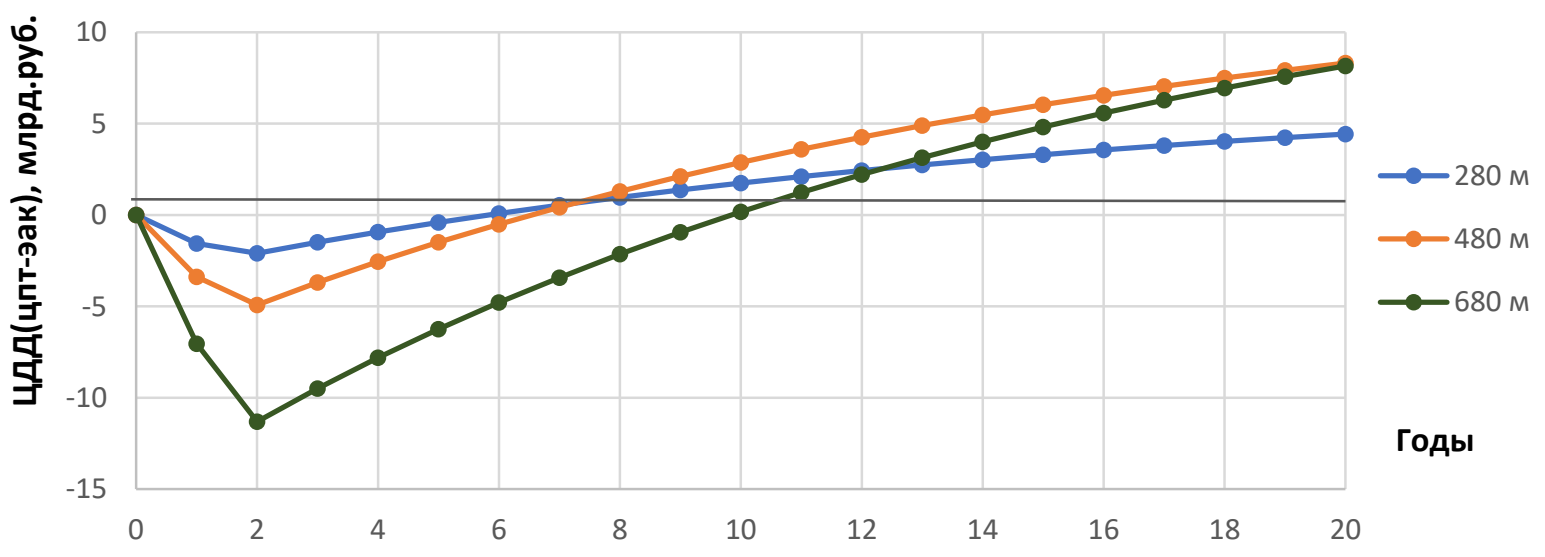

Рис. 3. Чистый дисконтированный доход при оценке дополнительных инвестиций в ЦПТ для породного комплекса производительностью 20 млн $\mathrm{m} / 2$ од, размещаемого с разносом борта, при разной высоте подъема

Fig. 3. Net present value when evaluating additional investments in the CFT for a rock complex with a capacity of 20 million tons/year placed with a spread of the Board, at different lifting heights

Данные закономерности объясняют тот факт, что срок окупаемости дополнительных инвестиций растет не столь интенсивно: для варианта 680 м при пятикратном росте капитальных затрат относительно варианта 280 м срок возврата инвестиций увеличивается всего в 1,7 раза. В целом сроки окупаемости для разных горнотехнических условий лежат в пределах
4-7 лет для наиболее часто применяемых на практике вариантов, в целом охватывая диапазон до 10 лет, а в отдельных случаях до 15 лет (рис. 4).

Закономерность изменения графика срока окупаемости на рис. 4 аналогична картине зависимостей экономического эффекта на рис. 5. Минимум срока окупаемости соответствует максимуму экономического эф- 
фекта. Отметим, на графиках рис. 3-5 приведены периоды возврата дополнительных затрат на комплекс ЦПТ в сравнении с комплексом автомобильного транспорта. Истинный срок окупаемости инвестиций может отличаться от приведенных сроков на графиках (рис. 3-5) как в меньшую, так и большую сторону в зависимости от доходной части денежного потока.
При разном сроке оценки отличаются и картины наиболее выгодных вариантов комплексов ЦПТ (рис. 5). Так, на горизонте планирования 5 лет область наибольшего экономического эффекта находится в пределах высот подъема до 200-500 м при производительности 10-20 млн т. При лаге в 8 лет максимумы смещаются в зону 250-600 м и 15-30 млн т/год.

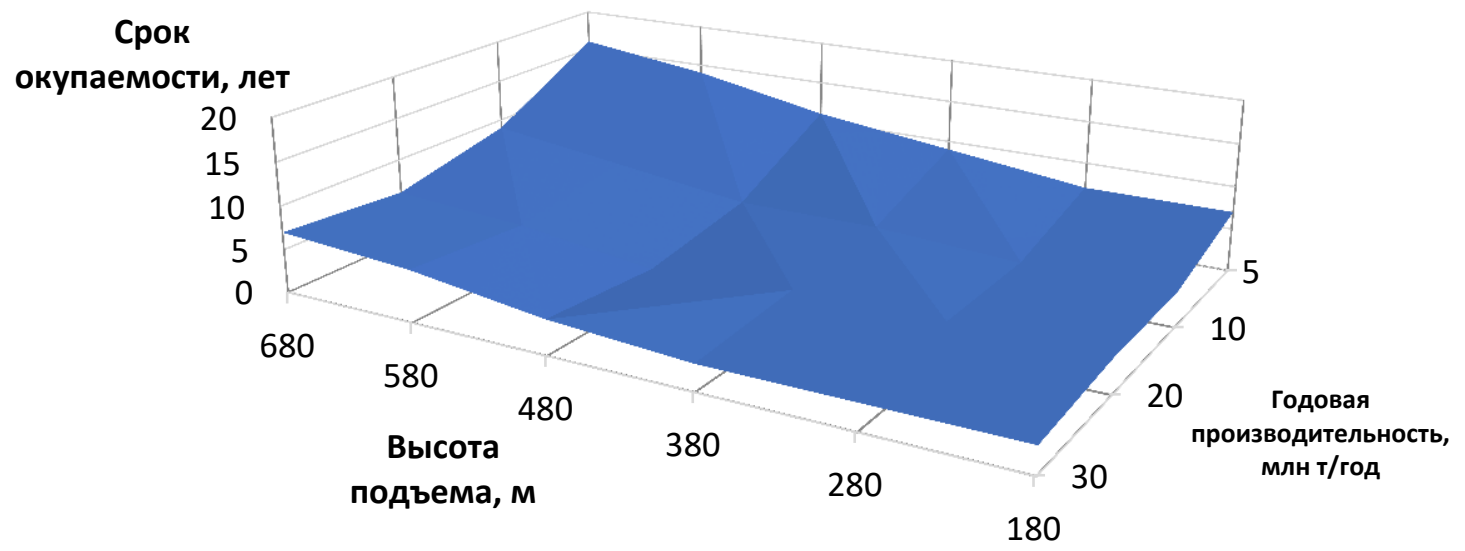

Pис. 4. Срок окупаемости дополнительных инвестиций на вскрышной комплекс ЦПТ с разносом борта карьера, учитываюший дисконтирование затрат, при различных технологических параметрах

Fig. 4. Payback period for additional investments in the overburden complex of the CFT with the spread of the quarry side, which takes into account the discounting of costs, under various technological parameters

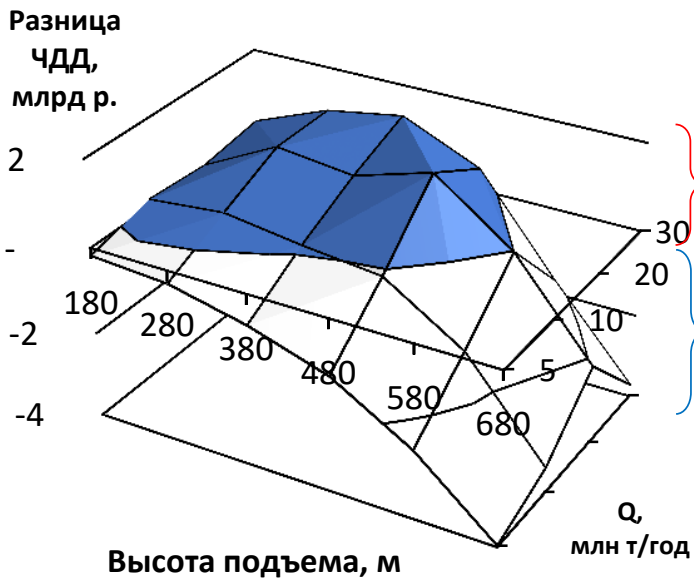

a/a

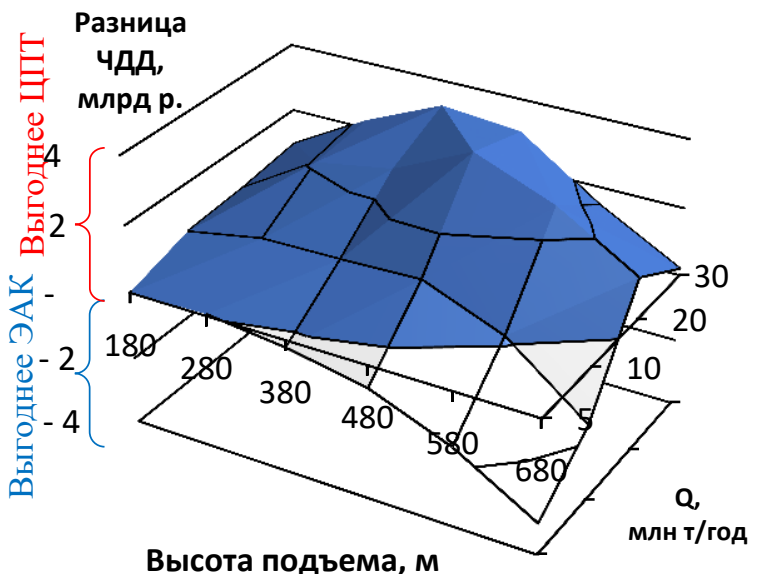

$\sigma / b$

Pис. 5. Разница чистого дисконтированного дохода между вариантами «ЦПТ с разносом борта» $и$ «ЭАК» при транспортировании вскрыши: а) срок оченки 5 лет; б) срок оценки 8 лет

Fig. 5. Difference in net present value between the options CFT with the spacing board and EAC during the transportation of overburden: a) evaluation period is 5 years; $b$ ) evaluation period is 8 years

Таким, образом использование методики ИГД УрО РАН позволяет не только выполнить оценку экономического эффекта в широком диапазоне горнотехнических условий, но и оптимизировать развитие транспортной системы во времени, рационально распределить инвестиционную нагрузку и максимизировать итоговый экономический эффект.

Рассмотрим более подробно различие вариантов схем размещения дробильно-конвейерных комплексов в карьерном пространстве (рис. 6). Основой экономического эффекта от применения конвейерного транспорта является сокращение эксплуатационных затрат, обусловленное:

- кратным сокращением парка автосамосвалов;

- использованием вместо дорогостоящего дизельного топлива более дешевой электрической энергии;

- существенным снижением количества необходимого персонала и др.

Ограничением возможного эффекта является рост капитальных затрат. Если в карьере имеется возможность разместить ДКК при минимальном объеме гор- 
но-капитальных работ, то инвестиции будут ниже, если же требуется разнос борта, то это накладывает ограничения как на возможную глубину ввода конвейера, так и на рентабельную производительность комплекса.

Результаты исследований области экономичного применения комплексов ЦПТ в сравнении с автомобильным транспортом представлены на рис. 6.

Варианты $a$ и $\sigma$ без разноса борта показывают рост экономического эффекта с увеличением высоты подъема до 350-400 м и его стабилизацию до глубин 680 м. А вот разнос борта (рис. 6, в, г) оказывает существенное отрицательное влияние при больших глубинах, поэтому после аналогичного роста до 350 400 м эффект начинается снижается уже при 550 м, заметно падая при относительных отметках 680 м.

Аналогичное влияние оказывает наращивание производительности ДКК: чем она больше, тем шире конвейер с возможным увеличением до двух параллельно размещаемых ставов. Это влияет на ширину конвейерной полутраншеи на борту карьера и приводит к соответствующему увеличению затрат на горно-капитальные работы. По графикам рис. 6, в, г видно, что разнос борта снижает эффективность ЦПТ после достижения пика при 20 млн т/год. В схемах без разноса борта такого эффекта не наблюдается.

Таким образом, показаны области эффективного применения комплексов ЦПТ в сравнении с ЭАК (рис. 6):

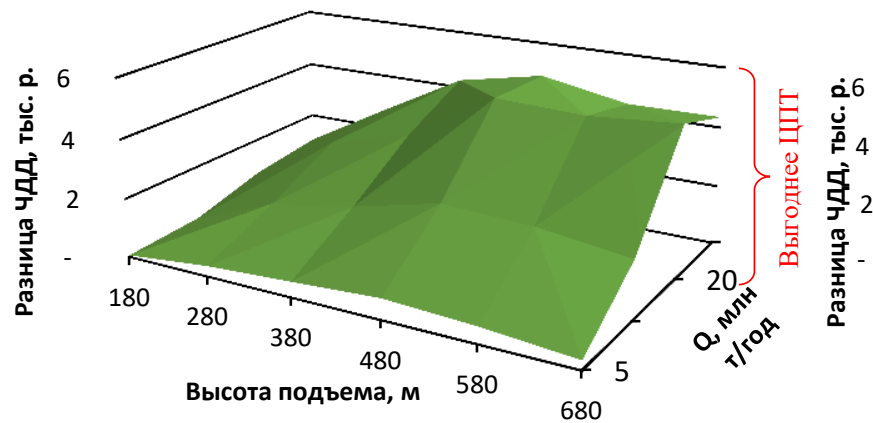

$a / a$

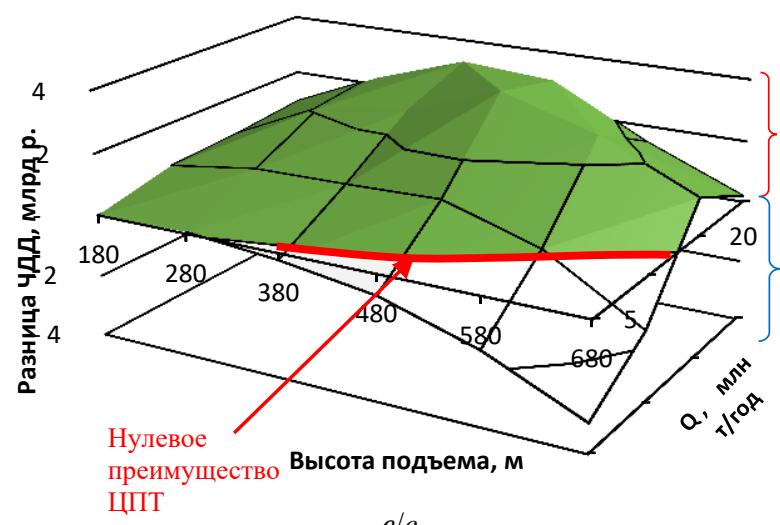

$B / c$
- рациональное размещения комплексов ЦПТ без разноса борта карьера имеет экономическую выгоду во всех рассмотренных горнотехнических условиях (рис. $6, a$, б);

- область более экономичного применения ЦПТ в случае необходимости разноса борта под размещение ДКК определяются следующими границами: 5 до 17,5 млн т/год и высоте подъема горной массы от 300 до 680 м для вскрышного комплекса, для рудного комплекса при производительностях от 5 до 14,5 млн т/год и высоте подъема от 400 до 680 м (рис. 6, в, г).

Решением проблемы при невозможности разместить в карьер высокопроизводительный ДКК без разноса борта является пересмотр транспортной системы в сторону меньшего грузопотока на конвейерный транспорт и/или меньшей глубины установки дробильно-перегрузочного пункта, либо переход на крутонаклонные конвейеры различной конструкции [19-23] с оптимизацией схемы их установки.

Углубленный анализ зависимостей параметров и технико-экономических показателей ЦПТ от горнотехнических факторов, схем размещения ДКК и организации работы комплекса, который позволяет выполнить методика ИГД УрО РАН, обеспечивает эффективное внедрение ЦПТ на горнодобывающих предприятиях даже в сложных условиях, расширяя тем самым область ее применения.

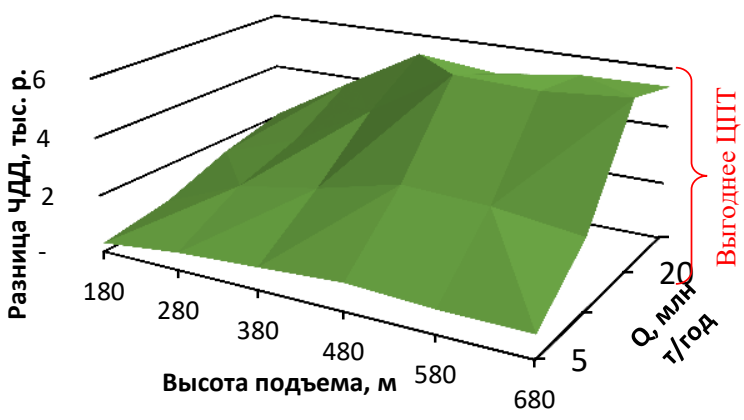

$\sigma / b$

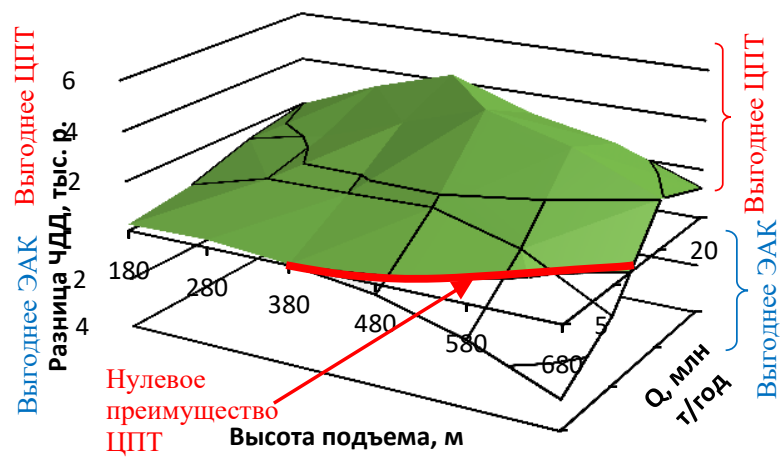

2/d

Рис. 6. Разница чистого дисконтированного дохода между вариантами использования ЦПТ и автомобильного транспорта: а) Вскрышной комплекс. Без разноса борта; б) Рудный комплекс. Без разноса борта; в) Вскрышной комплекс. С разносом борта; г) Рудный комплекс. С разносом борта

Fig. 6. Difference between the net present value between the options for using the CFT and automobile transport: a) Stripping complex. Without side spacing; b) Ore complex. Without side spacing; c) Stripping complex. With the spread of the Board; d) Ore complex. With the spread of the Board 


\section{Выводы}

1. В последние пять лет возрос интерес российских горнодобывающих предприятий к ЦПТ, основанной на применении автомобильно-конвейерного транспорта, для доставки руды из карьеров. Определенным ограничением ее широкого распространения является значительная капиталоемкость. Поэтому необходимо применение методик, обеспечивающих достоверный расчет окупаемости проекта и оптимизацию его техникоэкономических параметров.

2. В Институте горного дела Уральского отделения Российской академии наук разработана достаточно простая и удобная на практике методика обоснования параметров ЦПТ на основе техникоэкономической эффективности конструктивных и технологических решений. Она позволяет оценить затраты в сравнении с автомобильным транспортом как в относительных единицах, так и в абсолютных стоимостных показателях (в том числе чистый дисконтированный доход). Имея приемлемую точность расчетов, она отличается охватом широкого диапазона горнотехнических условий и возможностью учета большого количества значимых факторов.

3. В результате исследований установлено, что область наиболее экономичного применения ЦПТ с ленточными конвейерами стандартного уклона

\section{СПИСОК ЛИТЕРАТУРЫ}

1. Аброськин А.С. Применение современных систем автоматизации на открытых горных работах // Известия Томского политехнического университета. Инжиниринг георесурсов. 2015. - T. 326. - № 12. - C. 122-130.

2. Nel S., Kizil M.S., Knights P. Improving truck-shovel matching // Proceedings of the 35th APCOM Symposium / Eds. E.Y. Baafi, R.J. Kinimonth, I. Porter. -Wollongong, NSW, Australia, 24-30 September 2011. - P. 381-391.

3. Bozorgebrahimi E. The evaluation of haulage truck size effects on open pit mining: Thesis for Doctor Philosophy. - British Columbia 2004. - 177 p.

4. Burt C.N., Caccetta L. Equipment selection for surface mining. A review // Interfaces. - 2014. - V. 44 (2). - P. 143-162.

5. Radlowski J. In-Pit crushing and Conveying as an alternative to all truck system in open pit mines: Thesis for Master of Applied Science. - British Columbia, 1988. - 286 p.

6. Isaac D., Peter K., Kizil M.S. Truck and shovel versus in-pit conveyors systems: a comparison of the valuable operating time // Coal Operators' Conference. - Wolloongong: The University of Wolloongong, 2016. - P. 463-476.

7. Оленегорский ГОК запустил дробильный комплекс в карьере с КНК // Официальный сайт Северсталь. URL: https://olcon.ru/rus/press_ center/news/document1510.phtml (дата обращения: 04.04.2020).

8. «Металлоинвест» планирует вложить 64 млрд рублей до 2024 года в модернизацию ГОКов. URL: https://tass.ru/ekonomika/ 6980305 (дата обращения: 04.04.2020).

9. На Михайловском ГОКе продолжается строительство дробильно-конвейерного комплекса // Железногорские новости: общественно-политическая городская газета. URL: https://ferumnews.ru/news/ekonomika/mikhailovsky-gokcontinues-the-cons/ (дата обращения: 04.04.2020).

10. Инновационные технологии на Михеевском ГОКе // Rusmet: новости. URL: https://rusmet.ru/innovacionnye_tehnologii_na_ miheevskom goke/ (дата обращения: 24.03.2020).

11. «МИХЕЕВСКИЙ ГОК»// Сайт. Русская медная компания. URL: http://rmk-group.ru/ru/activities/enterprises/mikheevsky/ (дата обращения: 24.03.2020). (до $16^{\circ}$ ) при разносе борта карьера под ДКК по затратам на транспорт ограничивается замкнутой кривой эллипсовидной формы в пределах диапазона технологических параметров: производительность 10-25 млн т/год, высота подъема 250600 м. Применение специальных схем размещения ДКК с минимальным объемом горно-капитальных работ обеспечивает расширение области эффективного применения ЦПТ.

4. Границы области эффективного применения ЦПТ, установленные на основе абсолютных стоимостных показателей, соответствуют аналогичным ограничениям, определенным по относительным удельным затратам ([p./т (цпт)]/[p./т (авто) $]<1)$. Следовательно, предварительный выбор варианта ЦПТ для последующего сравнения, а также укрупненная оценка могут выполняться на основе экспресс-методики, изложенной в [13].

5. Использование разработанной методики позволяет не только выполнить оценку экономического эффекта в широком диапазоне горнотехнических условий, но и оптимизировать развитие транспортной системы во времени, рационально распределить инвестиционную нагрузку и максимизировать итоговый экономический эффект.

Исследования выполнены в рамках Государственного задания №ГР АААA-A19-119020790025-4.

12. Семенкин А.В., Антонов В.А.Исследование экономического показателя затрат при циклично-поточной технологии на рудных карьерах // Известия вузов. Горный журнал. - 2019. № 1. - C. 103-111. DOI: 10.21440/0536-1028-2019-1-103-111

13. Журавлев А.Г. Вопросы оптимизации параметров транспортных систем карьеров // Горный информационноаналитический бюллетень. - 2020. - № 3-1. - С. 584-602.

14. Новые подходы и решения по применению цикличнопоточной технологии на карьерах / А.В. Глебов, В.А. Берсенев, Г.Д. Кармаев, А.В. Семенкин // Горный журнал. - 2017. № 6. - C. 49-52.

15. Семенкин А.В. Учет фактора времени при определении эффективности применения комплексов ЦПТ // Известия УГГУ. - 2017. - № 1. - С. 72-75.

16. Груздев А.В., Осадчий А.М., Фурин В.О. Стационарные и полустационарные дробильно-перегрузочные установки ОАО «Уралмашзавод» // Горная Промышленность. - 2012. - № 4. C. $98-100$.

17. Argimbaev K.R., Maya B.O. The experience of the introduction of mobile crushing and screening complexes on a deposit of building materials // Research journal of applied science. - 2016. - V. 11. № 6. - P. 300-303.

18. Методические рекомендации по оценке эффективности инвестиционных проектов: утв. Минэкономики РФ, Минфином РФ и Госстроем РФ от 21 июня 1999 г. N BK 477. URL: http://docs.cntd.ru/document/1200005634 (дата обращения: 13.04.2020).

19. Dos Santos J.A. Sandwich belt high angle conveyors coal mine to prep plant and beyond // Proceedings of the XVIII International Coal Preparation Congress. - Cham: Springer International Publishing, 2016. - P. 111-118

20. Minkin A., Bötsting P., Becker N. Pipe conveying the next stage a new technology for steep incline high capacity open pit conveying // Bulk Solids Handling. - 2016. - № 2/3. URL: https://news.bulk-online.com/category/bulk-solids-handlingarchive (дата обращения: 20.04.2020).

21. Glebov A.V., Karmaev G.D., Bersenev V.A. Innovative engineering design of the high-angle conveyor for mining of deepseated mineral deposits // Aspects in Mining and Mineral 
Science. - 2018. - V. 2. - № 2. - P. 233-239. DOI: 10.31031/AMMS.2018.02.000535

22. Paelke J.W., Ginther R., Kessler F. Преимущества вертикальных конвейерных систем POCKETLIFT и POCKETROРЕ по сравнению с традиционными системами вертикальной транспор- тировки сыпучих материалов // Горная промышленность. 2007. - № 5 (75). - C. 24-29.

23. Paelke J.W., Wilsher M. Flexowell Conveyor Technology // Bulk solids handling. - 1987. - V. 7. - № 2. - P. 2-20.

Поступила 08.09.2020 2.

\section{Информация об авторах}

журавлев $\boldsymbol{A . \Gamma . , ~ к а н д и д а т ~ т е х н и ч е с к и х ~ н а у к , ~ з а в е д у ю щ и и ̆ ~ л а б о р а т о р и е и ̆ , ~ И н с т и т у т ~ г о р н о г о ~ д е л а ~ У р а л ь с к о г о ~}$ отделения Российской академии наук.

Семенкин A.B., младший научный сотрудник, Институт горного дела Уральского отделения Российской академии наук. 
UDC 622.271.3.06:658.527

\title{
EVALUATION OF THE EFFECTIVENESS OF THE CYCLIC-FLOW TECHNOLOGY IN THE MODERN QUARRIES
}

\author{
Artem G. Zhuravlev'1, \\ juravlev@igduran.ru
}

\author{
Aleksandr V. Semenkin ${ }^{1}$, \\ semenkin@Igduran.ru \\ 1 Institute of Mining of Ural branch of RAS, \\ 58, Mamin-Sibiryak street, Ekaterinburg, 620219, Russia.
}

The relevance of the research lies in the fact that the use of cyclic flow technology in rational conditions for it allows you to significantly reduce the cost of transporting rock mass, but it has features and limitations, in particular, a large amount of capital expenditures. Therefore, it is necessary to use methods that ensure reliable calculation of the project's payback and optimization of its technical and economic parameters.

Objective: based on the analysis of net present value to determine the areas of economical application of cycle-flow technology complexes in comparison with excavator-automobile complexes.

Objects: mining factors of complexes of cyclical-flow technology and excavator-automobile complexes (annual productivity, height of lifting of rock mass, type of transported rock mass, technological features of placement of crushing and conveyor complex in the quarry space).

Methods: scientific and techno-economic analysis, graphic.

Results. The article provides an overview of the use of modern cyclic-flow technology complexes in Russian quarries; shows the results of calculating the economic effect of the complexes compared with the excavator-automobile complexes by the method developed in mining Institute Ural branch Russian Academy of Sciences. The study determined the payback period of additional investment for Stripping complex of cyclic-flow technology with the spacing side of the pit, taking into account the discounting of costs at different process parameters (lift height of rock mass from 180 to $680 \mathrm{~m}$, the annual capacity of the complexes range from 5 to 30 million MT/year). It shows the change in the difference in net present value for the variants of the cyclic-flow technology-excavator-automobile complexes depending on the mining parameters of the complexes. The area of the most economical application of the cyclic-flow technology with belt conveyors of a standard slope (up to $16^{\circ}$ ) when the side of the quarry is spread under the crushing and conveyor complex at the cost of transport was established.

\section{Key words:}

Cyclic-flow technology, crushing and conveyor complex, technical and economic comparison, application area, belt conveyor.

The study was supported within the framework of State Contract No. 075-00581-19-00, Project No. 0405-2019-0007.

\section{REFERENCES}

1. Abroskin A.S. Use of modern systems of automation of open cast mining. Bulletin of the Tomsk Polytechnic University. Geo Assets Engineering, 2015, vol. 326, no. 12, pp. 122-130. In Rus.

2. Nel S., Kizil M.S., Knights P. Improving truck-shovel matching. Proc. of the $35^{\text {th }}$ APCOM Symposium. Eds. E.Y. Baafi, R.J. Kinimonth, I. Porter. Wollongong, NSW, Australia, 24-30 September 2011. pp. 381-391.

3. Bozorgebrahimi E. The evaluation of haulage truck size effects on open pit mining. Thesis for Doctor Philosophy. British Columbia, 2004. $177 \mathrm{p}$

4. Burt C.N., Caccetta L. Equipment selection for surface mining. A review. Interfaces, 2014, vol. 44 (2), pp. 143-162.

5. Radlowski J. In-pit crushing and conveying as an alternative to all truck system in open pit mines. Thesis for Master of Applied Science. British Columbia, 1988, 286 p.

6. Isaac D., Peter K., Kizil M.S. Truck and shovel versus in-pit conveyors systems: a comparison of the valuable operating time. Coal Operators' Conference. Wolloongong, the University of Wolloongong Publ., 2016. pp. 463-476.

7. Olenegorskiy GOK zapustil drobilny kompleks $v$ karere s KNK Ofitsialny sajt Severstal [Olenegorsky GOK launched a crushing complex in a quarry with0020CNC. Official website of Severstal]. Available at: https://olcon.ru/rus/press_center/news/ document1510.phtml (accessed 4 April 2020).

8. «Metalloinvest» planiruet vlozhit 64 mlrd rubley do 2024 goda v modernizatsiyu GOKov [Metalloinvest plans to invest 64 billion rubles by 2024 in the modernization of GOK]. Available at: https://tass.ru/ekonomika/6980305 (accessed 4 April 2020).
9. Na Mihajlovskom GOKe prodolzhaetsya stroitelstvo drobilnokonveyernogo kompleksa. Zheleznogorskie novosti: obshchestvenno-politicheskaya gorodskaya gazeta [Construction of a crushing and conveyor complex continues at Mikhailovsky GOK Zheleznogorsk news: socio-political city newspaper]. Available at: https://ferumnews.ru/news/ekonomika/mikhailovsky-gokcontinues-the-cons/ (accessed 4 April 2020).

10. Innovatsionnye tekhnologii na Mikheevskom GOKe. Rusmet: novosti [Innovative technologies at the Mikheevsky GOK. Rusmet: news]. Available at: https://rusmet.ru/innovacionnye_ tehnologii_na_miheevskom_goke/ (accessed 24 March 2020).

11. "MIHEEVSKIY GOK». Sajt. Russkaya mednaya kompaniya [MIKHEEVSKY GOK. Website. Russian copper company]. Available at: http://rmk-group.ru/ru/activities/enterprises/mikheevsky/ (accessed 24 March 2020).

12. Semenkin A.V., Antonov V.A. Study of the economic cost indicator for cyclical-flow technology in ore quarries. University news. Mining journal, 2019, no. 1, pp. 103-111. In Rus.

13. Zhuravlev A.G. The issues of optimization of parameters of opencut transport systems. Mining information and analytical Bulletin, 2020, no. 3-1, pp. 584-602. In Rus.

14. Glebov A.V., Bersenev V.A., Karmaev G.D., Semenkin A.V. New approaches and solutions for the use of cyclical-flow technology in quarries. Mining journal, 2017, no. 6, pp. 49-52. In Rus.

15. Semenkin A.V. Taking into account the time factor in determining the effectiveness of the use of CFT complexes. UGGU news, 2017, no. 1, pp. 72-75. In Rus.

16. Gruzdev A.V., Osadchiy A.M., Furin V.O. Stationary and semistationary crushing and reloading plants of «Uralmashzavod». Mining, 2012, no. 4, pp. 98-100. In Rus. 
17. Argimbaev K.R., Maya B.O. The experience of the introduction of mobile crushing and screening complexes on a deposit of building materials. Research journal of applied science, 2016, vol. 11, no. 6, pp. 300-303.

18. Metodicheskie rekomendacii po otsenke effektivnosti investicionnykh proektov: utv. Minekonomiki RF, Minfinom RF i Gosstroem $R F$ ot 21 iyunya $1999 \mathrm{~g} . \mathrm{N}$ VK 477 [Methodological recommendations for evaluating the effectiveness of investment projects: approved. Ministry of economy of the Russian Federation, the Ministry of Finance and Gosstroy of the Russian Federation from June 211999 N VK 477]. Available at: http://docs.cntd.ru/ document/1200005634 (accessed 13 April 2020).

19. Dos Santos J.A. Sandwich belt high angle conveyors coal mine to prep plant and beyond. Proc. of the XVIII International Coal Preparation Congress. Cham, Springer International Publishing, 2016. pp. 111-118.
20. Minkin A., Bötsting P., Becker N. Pipe conveying the next stage a new technology for steep incline high capacity open pit conveying. Bulk Solids Handling, 2016, no. 2/3. Available at: https://news.bulk-online.com/category/bulk-solids-handlingarchive (accessed 20 April 2020).

21. Glebov A.V., Karmaev G.D., Bersenev V.A. Innovative engineering design of the high-angle conveyor for mining of deep-seated mineral deposits. Aspects in Mining and Mineral Science, 2018, vol. 2, no. 2, pp. 233-239.

22. Paelke J.W., Ginther R., Kessler F. Advantages of vertical conveyor systems POCKETLIFT and POCKETROPE compared to traditional systems of vertical transportation of bulk materials. Mining, 2007, no. 5 (35), pp. 24-29. In Rus.

23. Paelke J.W., Wilsher M. Flexowell Conveyor Technology. Bulk solids handling, 1987, vol. 7, no. 2, pp. 2-20.

Received: 8 September 2020.

\section{Information about the authors}

Artem G. Zhuravlev, Cand. Sc., assistant professor, laboratory chief, Institute of Mining of Ural branch of RAS. Aleksandr V. Semenkin, junior researcher, Institute of Mining of Ural branch of RAS. 